\title{
Indigo: universal cheminformatics API
}

\author{
D Pavlov*, M Rybalkin, B Karulin, M Kozhevnikov, A Savelyev, A Churinov \\ From 6th German Conference on Chemoinformatics, GCC 2010 \\ Goslar, Germany. 7-9 November 2010
}

Indigo is a universal portable open-source library which allows developers and chemists to solve various cheminformatics tasks. The library has grown out from a collection of more specific tools we have developed during the past years. Proper wrappers for popular programming languages are provided, as well as some command-line and GUI tools useful for scientists. All software is available under the terms of the GPL license.

The core of Indigo is a $\mathrm{C}++$ cheminformatics library, which has been developed with two things in mind: performance and important chemical features. Plain $\mathrm{C}$ wrapper is provided for the core library, and other wrappers are built around it for Python, Java, and C\# languages (support of Ruby is coming soon). The main chemical features of Indigo are:

- Support of popular chemistry formats: Molfiles/ Rxnfiles v2000 and v3000, SDF, RDF, SMILES, SMARTS, SMIRKS

- Tehrahedral and cis-trans stereochemistry support

- Molecule and reaction rendering to PNG, SVG, PDF files

- Molecule and reaction layout (depiction)

- Aromatization and kekulization

- Canonical (isomeric) SMILES computation

- Exact and substructure matching for molecule and reactions, SMARTS and SMIRKS

- matching, highlighting support

- Matching or tautomers and resonance structures

- Molecule and reaction fingerprinting, similarity computation

- Molecular weight, molecular formula computation

- Maximum Common Substructure (MCS) computation

- R-Group deconvolution and scaffold detection

- Combinatorial chemistry

* Correspondence: dpavlov@scitouch.net

SciTouch LLC, St.-Petersburg, Russia
The pre-compiled static and dynamic binaries of the Indigo library are available, as well as binaries of command-line utilities and GUI tools. The library allows multi-threaded use. All binaries are provided for Windows, Linux and Mac OS X, both 32-bit and 64-bit Intel architectures.

The site of Indigo is http://scitouch.net/indigo (to be opened in August 2010).

Published: 19 April 2011

doi:10.1186/1758-2946-3-S1-P4

Cite this article as: Pavlov et al:: Indigo: universal cheminformatics API.

Journal of Cheminformatics 2011 3(Suppl 1):P4.

\section{Publish with ChemistryCentral and every scientist can read your work free of charge \\ "Open access provides opportunities to our colleagues in other parts of the globe, by allowing anyone to view the content free of charge." \\ W. Jeffery Hurst, The Hershey Company. \\ - available free of charge to the entire scientific community \\ - peer reviewed and published immediately upon acceptance \\ - cited in PubMed and archived on PubMed Central \\ - yours - you keep the copyright \\ Submit your manuscript here: \\ http://www.chemistrycentral.com/manuscript/}

